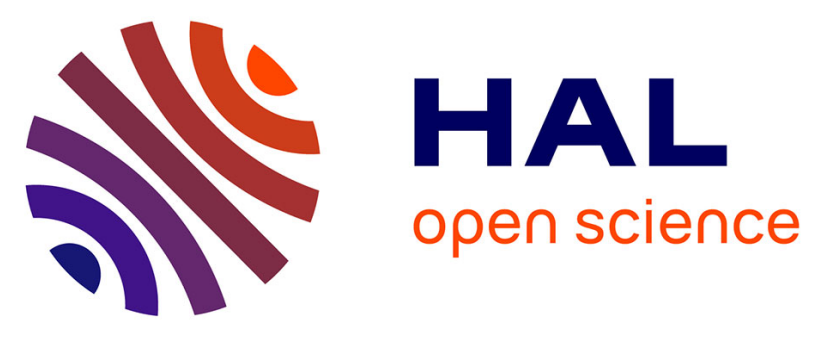

\title{
Linking seascape with landscape genetics: Oceanic currents favour colonization across the Galápagos Islands by a coastal plant
}

Yurena Arjona, Javier Fernández-López, Miguel Navascués, Nadir Alvarez, Manuel Nogales, Pablo Vargas

\section{To cite this version:}

Yurena Arjona, Javier Fernández-López, Miguel Navascués, Nadir Alvarez, Manuel Nogales, et al.. Linking seascape with landscape genetics: Oceanic currents favour colonization across the Galápagos Islands by a coastal plant. Journal of Biogeography, 2020, 47 (12), pp.2622-2633. 10.1111/jbi.13967 . hal-02959841

\section{HAL Id: hal-02959841 \\ https://hal.inrae.fr/hal-02959841}

Submitted on 7 Oct 2020

HAL is a multi-disciplinary open access archive for the deposit and dissemination of scientific research documents, whether they are published or not. The documents may come from teaching and research institutions in France or abroad, or from public or private research centers.
L'archive ouverte pluridisciplinaire HAL, est destinée au dépôt et à la diffusion de documents scientifiques de niveau recherche, publiés ou non, émanant des établissements d'enseignement et de recherche français ou étrangers, des laboratoires publics ou privés.

\section{(ㄷ)(1) $\$$}

Distributed under a Creative Commons Attribution - NonCommerciall 4.0 International 


\title{
Linking seascape with landscape genetics: Oceanic currents favour colonization across the Galápagos Islands by a coastal plant
}

\author{
Yurena Arjona $^{1}$ (i) | Javier Fernández-López ${ }^{1}$ (i) | Miguel Navascués ${ }^{2}$ (i) | \\ Nadir Alvarez ${ }^{3}$ (D) | Manuel Nogales ${ }^{4}$ (D) | Pablo Vargas ${ }^{1}$
}

${ }^{1}$ Real Jardín Botánico (RJB-CSIC), Madrid, Spain

${ }^{2}$ CBGP, Univ Montpellier, CIRAD, INRA, Montpellier SupAgro, Montpellier, France

${ }^{3}$ Museum of Natural History of the City of Geneva, Genève, Switzerland

${ }^{4}$ Island Ecology and Evolution Research Group (IPNA-CSIC), San Cristóbal de La Laguna, Spain

\section{Correspondence}

Yurena Arjona, Instituto de Productos Naturales y Agrobiología (IPNA-CSIC). Avda. Astrofísico Francisco Sánchez 3, 38206 San Cristóbal de La Laguna, Tenerife, Canary Islands, Spain.

Email:yurenaaf@gmail.com

\section{Present address}

Yurena Arjona, Present address: Island Ecology and Evolution Research Group (IPNA-CSIC), San Cristóbal de La Laguna, Spain

Javier Fernández-López, Instituto de Investigación en Recursos Cinegéticos, Ciudad Real, Spain

Funding information

Ministerio de Economía y Competitividad, Grant/Award Number: BES-2013-062843, CGL2012-C02-01, EEBB-I-15-10273 and EEBB-I-16-11437

Handling Editor: Ceridwen Fraser

\begin{abstract}
Aim: Coastal plants are terrestrial organisms for which ocean surface currents often act as long-distance dispersal vectors (thalassochorous species) favouring broad distributions and connecting distant populations. However, few studies have statistically assessed the role of currents in modulating gene flow and species distributions of terrestrial organisms. Here we evaluate the hypothesis that some thalassochorous plants exhibit population connectivity, presumably due to effective seed dispersal driven by sea currents.

Location: Galápagos Islands (Ecuador).

Taxon: Salt bush (Cryptocarpus pyriformis Kunth), a Galápagos native and locally widespread coastal angiosperm.

Methods: Using 1806 SNPs obtained by ddRADseq, we evaluated the genetic structure and differentiation of the Galápagos salt bush. To assess the role of sea currents in modulating inter-population gene flow, four explicit hypotheses were tested using reciprocal causal modelling and spatial eigenvector analysis: (a) isolation by sea resistance, considering that only sea dispersal is possible; (b) isolation by sea and inland resistance, considering that inland dispersal is also possible; (c) isolation by barrier, considering the sea as an obstacle to seed dispersal; and (d) isolation by geographical distance.

Results: Low differentiation and little genetic structure were detected among populations of $C$. pyriformis. Pairwise genetic distances between populations from different islands were significantly correlated with cost distances calculated from sea-current direction and speed. Nonetheless, inland dispersal also accounted for some gene flow within each island.

Main conclusion: Extensive and frequent seed dispersal by sea has apparently favoured strong inter-island genetic connectivity within Galápagos. A combination of methods developed for terrestrial and marine domains (landscape and seascape genetics) aids in understanding how landscape features modulate gene flow of coastal plant species, as these terrestrial organisms are highly dependent on the sea for seed dispersal.
\end{abstract}




\section{KEYWORDS}

directional dispersal, isolation by resistance, oceanic islands, population genetics, salt bush, thalassochory

\section{1 | INTRODUCTION}

Oceans cover around $71 \%$ of the Earth surface, isolating landmasses and hence the terrestrial organisms that occupy them. At the same time, sea currents act as an essential vector for propagules of land organisms, transporting them across long distances, connecting inhabited landmasses and allowing colonization of oceanic islands that emerge lifeless from the seafloor (Abe, 2006; Magnússon, Magnússon, Ólafsson, \& Sigurdsson, 2014; Ridley, 1930). Plant species specialized for sea dispersal are referred to as thalassochorous. They are able to develop floating diaspores that survive a long time in seawater, which favours their arrival and germination in new territories (van der Pijl, 1982; Ridley, 1930).

Thalassochorous plants usually have wide distributions (Miryeganeh, Takayama, Tateishi, \& Kajita, 2014), which points to the efficiency of the thalassochorous dispersal syndrome in long-distance dispersal (hereafter LDD). Coastal plants, due to their proximity to the sea, are salt tolerant and many of them develop diaspores with corky or fibrous tissues, air chambers and a diverse array of structures that help them float for long periods over the sea. This set of traits defines the thalassochorous dispersal syndrome (Heleno \& Vargas, 2015; van der Pijl, 1982; Ridley, 1930). Darwin (1859) experimentally demonstrated the ability of certain plant species to float for a long time and germinate after immersion in salt water, which has been confirmed by subsequent studies reporting a wide variety of coastal species that are able to float for months in salt water and germinate afterwards (Esteves, Costa, Vargas, Freitas, \& Heleno, 2015; Guja, Merritt, \& Dixon, 2010; Nakanishi, 1988). Such high dispersal ability and salt tolerance of thalassochorous plants have favoured the early colonization of oceanic islands (Abe, 2006; Magnússon et al., 2014), the recolonization of disturbed areas and genetic connectivity between distant populations by the exchange of diaspores (Cerón-Souza et al., 2015; Takayama, Tateishi, Murata, \& Kajita, 2008). In principle, gene flow between sea-dispersed plant populations should be highly influenced by sea current properties, such as directionality and speed, which should be major drivers in shaping their population genetic structure (Gallaher, Callmander, Buerki, Setsuko, \& Keeley, 2017).

Understanding the effect of landscape features on gene flow between populations of terrestrial organisms is one of the objectives of landscape genetics (Manel \& Holderegger, 2013). In contrast to terrestrial organisms, marine organism gene flow is highly influenced by seascape features. As a consequence, seascape genetics was developed as a discipline closely related to landscape genetics to cope with the particular biology of many marine organisms-that is, wide distributions, high dispersibility and little genetic structureand physical properties of the ocean (Riginos \& Liggins, 2013; Selkoe et al., 2016). Coastal plant species are in an intermediate situation, being terrestrial organisms that are mainly sea dispersed but capable of dispersal over land. Although many phylogeographical studies suggest that ocean currents are responsible for the genetic structuring patterns found (e.g. Gallaher et al., 2017; Miryeganeh et al., 2014; Takayama et al., 2008), few studies have specifically addressed the extent to which direction and speed of sea currents modulate gene flow among coastal plant populations (e.g. see Hodel et al., 2018). A combination of methods employed in landscape and seascape genetics is the best option to address this issue.

Cryptocarpus pyriformis Kunth (Nyctaginaceae) -commonly known as salt bush or monte salado - is distributed along the coasts of Galápagos, mainland Ecuador and Peru (Wiggins \& Porter, 1971). The Galápagos archipelago, located in the Pacific Ocean about 1,000 km west of mainland Ecuador, hosts many populations of salt bush, occurring on all 13 largest islands (Jaramillo Díaz, Guézou, Mauchamp, $\&$ Tye, 2018). The small flowers of $C$. pyriformis are mainly pollinated by insects, with ants being the most frequent visitor of the plants in the Galápagos (Traveset et al., 2013). Its fruits are small, pear-shaped and have a corky consistency that helps them to float on salt water (Y. Arjona and P. Vargas, pers. obs.). Galápagos finches feed on salt bush fruits and intact seeds have been found in lava lizard droppings, although no conclusive results have been reported regarding effective dispersal by vertebrates (Heleno et al., 2011; Heleno, Olesen, Nogales, Vargas, \& Traveset, 2013). There is thus evidence of a dispersal potential over land as well as dispersal by sea in this species.

In this study, we evaluate the hypothesis that coastal thalassochorous species readily disperse by sea, which should be reflected by evidence of gene flow corresponding to the direction and speed of sea currents. With this aim we chose the widespread salt bush (Cryptocarpus pyriformis) as a case study and evaluated its dispersal across the Galápagos archipelago. We formulated four explicit hypotheses that consider different scenarios that vary in importance for inland and sea dispersal: (a) dispersal is largely mediated by sea and modulated by direction and speed of sea currents, whereas inland dispersal does not contribute to inter-population connectivity (isolation by sea resistance); (b) sea dispersal is the main driver of inter-island connectivity, and inland dispersal also contributes to genetic differentiation (isolation by inland and sea resistance); (c) the sea acts as a barrier to dispersal, isolating populations from different islands (isolation by barrier); and (d) isolation by geographical distance, with no effect of the context (island or sea; null hypothesis). Publicly available data on ocean circulation and genetic data-from hundreds of single nucleotide polymorphisms (SNPs) distributed across the whole genome-were analysed under a landscape genetic framework, to evaluate the role of sea current speed and direction in inter-island genetic differentiation of the salt bush across the Galápagos. 


\section{2 | MATERIALS AND METHODS}

\section{1 | Sampling, DNA extraction, ddRAD library preparation and SNP calling}

A total of 231 samples were collected from 12 of the 13 largest islands of the Galápagos (Baltra was excluded because of proximity to Santa Cruz and its recent land bridge), where we selected from one to five populations per island based on island size. Additionally, nine individuals were sampled from four populations along the coast of mainland Ecuador, to assess how divergent the Galápagos populations are from distant continental populations (Figure 1 and Table S1.1). DNA was extracted from silica-gel-dried leaf samples using DNeasy Plant Mini Kit (Qiagen, Inc., Valencia, CA, USA) and cleaned following the phenol-chloroform protocol to eliminate salts and other compounds that may interfere in further steps of the process. Double-digest restriction site associated DNA (ddRAD) libraries were prepared following the protocol described by Mastretta-Yanes et al. (2015), including 24 replicates. The ddRAD libraries were single-end sequenced on two lanes of Illumina HiSeq 2,500 at the Lausanne Genomic Technologies Facility.

Reads were demultiplexed and de novo assembled using 'ipyrad' v. 0.7.22 (Eaton, 2014). 'Trimmomatic' v. 0.36 (Bolger, Lohse, $\&$ Usadel, 2014) was used to remove the adapters and quality-trim the reads before the assembly. The 'ipyrad' clustering threshold and minimum depth parameters were set to 0.93 and 10 , respectively, as they rendered a good balance between the error rate and the number of SNPs recovered (Figure S2.1). The resultant SNP matrix was filtered using 'vcftools' v. 0.1.15 (Danecek et al., 2011); all sites with more than $70 \%$ and all individuals with more than $85 \%$

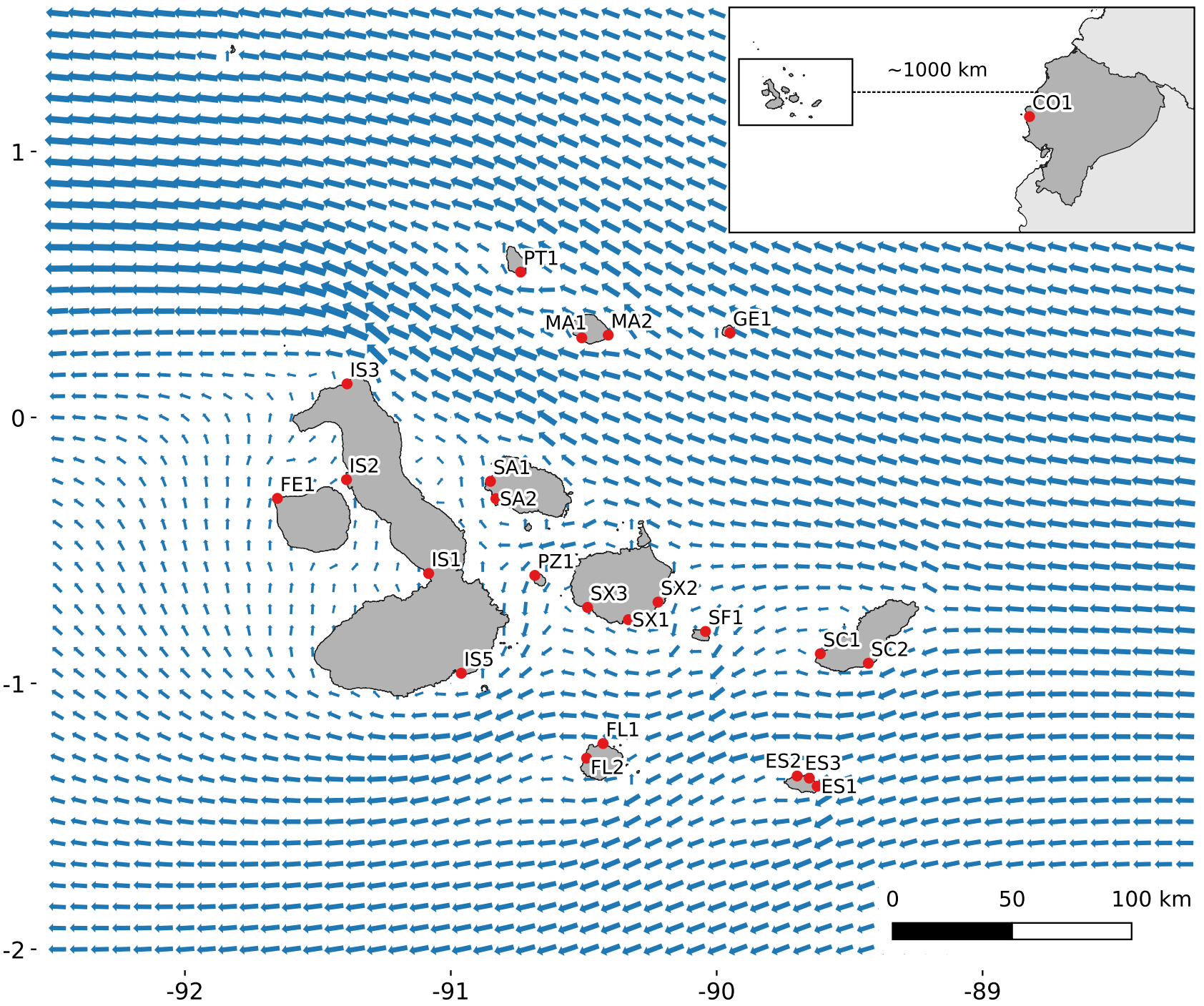

FIGURE 1 Galápagos archipelago and mean values of sea current speed and direction for the whole period analysed (1992-2018). Arrows indicate direction, their length and width are proportional to the speed of the sea currents. Location of the Galápagos archipelago is shown in the map (top right, mainland Ecuador in dark grey). Red dots indicate the position of Cryptocarpus pyriformis sample populations. CO: continent; ES: Española; SC: San Cristóbal; FL: Floreana; SF: Santa Fe; SX: Santa Cruz; PZ: Pinzón; SA: Santiago; IS: Isabela; FE: Fernandina; GE: Genovesa; MA: Marchena; PT: Pinta 
of missing data were removed, and only biallelic sites were kept. Additionally, custom scripts were employed to further modify 'ipyrad' output files to fit the input requirements of the software employed when necessary. See Appendix S2 for further details about ddRAD library preparation and bioinformatic processing of the reads.

\section{2 | Genetic diversity and population genetic structure}

Observed and expected heterozygosities $\left(H_{\mathrm{O}}, H_{\mathrm{E}}\right)$ and the inbreeding coefficient $\left(F_{I S}\right)$ were calculated across loci per population using 'GenAlEx' (Peakall \& Smouse, 2006, 2012). A Pearson's correlation was performed between heterozygosity and island size to evaluate a possible variation in genetic diversity based on different carrying capacities due to island size. Jost's D differentiation index (Jost, 2008), multilocus fixation index $G_{S T}$ (Nei \& Chesser, 1983), Weir and Cockerham's $F_{\mathrm{ST}}$ estimator- $\theta$ (Weir \& Cockerham, 1984)-across loci and population, and pairwise $\theta$ between populations, were estimated with the package 'diveRsity' (Keenan, Mcginnity, Cross, Crozier, \& Prodöhl, 2013) for the R software (R Development Core Team, 2017). Analyses of molecular variance (AMOVA; Excoffier, Smouse, \& Quattro, 1992) were performed to assess the proportion of variation between islands and between populations within islands using the r package 'poppr' (Kamvar, Tabima, \& Grünwald, 2014). To evaluate the degree to which genetic differentiation and genetic diversity increase when including very distant populations, we repeated the analysis including continental samples.

A principal component analysis (PCA) and a discriminant analysis of principal components (DAPC) were employed to explore the genetic variation among sampled individuals and the existence of genetically distinct groups of individuals. The groups assessed by DAPC can either be given by the k-means algorithm or defined by the user. We ran DAPC using both options, considering the 12 islands and the continent as groups defined by the user $(K=13)$. The number of principal components (PCs) retained in the analyses was selected based on the optimization of the $\alpha$-score to avoid over-fitting the results. To perform PCA and DAPC we used the $\mathrm{R}$ package 'adegenet' (Jombart, Devillard, \& Balloux, 2010). In addition, we used 'STRUCTURE' v. 2.3.4 (Falush, Stephens, \& Pritchard, 2003; Pritchard, Stephens, \& Donnelly, 2000) to assess population genetic structure. We ran the admixture model assuming correlated allele frequencies, with a lambda previously estimated as recommended by the authors, from $K=1$ to $K=13$, 10 times with 2,000,000 MCMC iterations and 200,000 iterations burn-in. To assess which value of $K$ was statistically preferred we used two methods: (a) $\Delta K$ (Evanno, Regnaut, \& Goudet, 2005); and (b) MedMeaK, MaxMeaK, MedMedK and MaxMedK (Puechmaille, 2016). These latter estimators were calculated using different thresholds $(0.5,0.6,0.7$ and 0.8), considering all the 23 Galápagos populations and the continent. The graphical output from the 'STRUCTURE' results was created using 'DISTRUCT' v.1.1 (Rosenberg, 2004).

\section{3 | Resistance due to ocean currents within Galápagos}

Resistance to seed dispersal due to ocean currents was estimated using publicly available data from the U.S. Naval Research Laboratory, specifically the HYCOM + NCODA Global $1 / 12^{\circ}$ Analysis (GLBu0.08) dataset (https://www.hycom.org/data/glbu0pt08). Data for the working area $\left(-92.5^{\circ}\right.$ and $-88.25^{\circ}$ east; $-2^{\circ}$ and $1.5^{\circ}$ north) were obtained via functions from the R package 'HMMoce' (Braun, Galuardi, \& Thorrold, 2018; https://github.com/cran/HMMoce/ blob/master/R/get.hycom.R). These data consisted of the eastward and northward components of seawater velocity $(\mathrm{m} / \mathrm{s})$ at the ocean surface for 4,771 days (measures taken every two days during the period from 2 October 1992 to 20 November 2018, see Figure 1 for a summary of these data). This extensive period of time was selected to include annual and seasonal variations in climatic conditions and ocean circulation, and because Cryptocarpus fruits are produced throughout the year.

Anisotropic cost-distance matrices between sampling localities were estimated based on the maximum connectivity within the period covered by the data. Firstly, for each day, raw data were converted into a raster layer from which the speed and direction of sea currents were calculated. Then, the cost to passively move between adjacent cells of the raster was calculated using the function flow.dispersion from the 'rWind' package (Fernández-López \& Schliep, 2018), modified to cope with missing data values corresponding to landmasses. This function implements the algorithm proposed by Muñoz, Felicísimo, Cabezas, Burgaz, and Martínez (2004), in which the cost is directly proportional to the difference between the direction of the movement trajectory towards the target cell and the direction of the sea current, and inversely proportional to sea current speed. For passive dispersal, movements against sea current flow are not permitted-that is, those for which the difference between their bearing and sea current direction is higher than $90^{\circ}$ (see Fernández-López \& Schliep, 2018). After their computation, transition costs among sea surface cells ranged between 0.1 and 32,004.9, with a mean of 310.7. Based on these costs, two resistance layers were calculated: (a) considering only sea dispersal is possible (infinite cost assigned to inland dispersal); and (b) that both inland and sea dispersal occur (a resistance of 0.1 assigned to all land cells-this is the minimum cost to move between adjacent cells assigned by the function, without considering sea current speed). A third resistance layer was built to account for the hypothesis of isolation due to barriers, where infinite cost was assigned to sea dispersal and a cost of 0.1 to the transition between adjacent land cells. With the transition costs between all adjacent cells, least-cost paths between populations were calculated using the 'gdistance' R package (van Etten, 2017). From the inverse of these costs we obtained the connectivity between pairs of populations. This procedure yielded 4,771 connectivity matrices, one for each day in the dataset, summarized into a single matrix per hypothesis by taking the maximum value per population pair and direction and converted them again into cost-distance values. To make this asymmetric matrix symmetric (i.e. to have costs from $A$ to $B$ and 
from $B$ to $A$ summarized into a single distance $A-B$ ), we calculated the mean value between the two connectivity values per population pair. Independently, additional cost distance matrices were calculated under each of the two resistance hypotheses for the rainy season (from December to May) and the dry season (from April to November) separately. Due to the proximity of Española's populations ES1 and ES3, the estimated connectivity between them was infinite. To avoid this extreme value affecting the results, we removed population ES3 for further analyses.

\section{4 | Isolation by resistance, barrier or geographical distance}

We proposed four alternative models that modulate gene flow between populations: (a) isolation by resistance due to ocean currents with no overland dispersal possible (IBR1); (b) isolation by resistance due to ocean currents and uniform low resistance in crossing landmasses (IBR2); (c) isolation by barrier (IBB) with islands being isolated due to the impossibility of crossing the sea barrier; and (d) isolation by geographical distance (IBD). The net contribution of the hypothesis components to the overall genetic variation was assessed using Mantel and partial Mantel tests in a reciprocal causal modelling framework and, independently, by decomposing the different distance matrices into eigenvector maps and using them as predictors in redundancy analyses.

\subsection{1 | Reciprocal causal modelling}

Pairwise genetic distances were calculated as $F_{\mathrm{ST}} /\left(1-F_{\mathrm{ST}}\right)$ using 'Genepop' 4.0 (Rousset, 2008) as recommended by Rousset (1997). Geographical distances were calculated using the R package 'raster' (Hijmans, 2018) as the natural logarithm of the distance between two points in the WGS ellipsoid to linearize the relationship with genetic distances. Cost distances mediated by sea currents for the two IBR and the IBB models were obtained as explained in the previous section, and were also log-transformed. The correlations between distance matrices were calculated using Mantel test (Mantel, 1967) and partial Mantel test (Smouse, Long, \& Sokal, 1986) using the 'vegan' R package (Oksanen et al., 2018). Partial Mantel statistics $\left(r_{M}\right)$ were then compared under reciprocal causal modelling, which reduces the high risk (reported for simple Mantel tests) of finding spurious correlations when comparing highly correlated alternative hypotheses (Cushman, Wasserman, Landguth, \& Shirk, 2013). For a pair of hypotheses $(\mathrm{H} 1$ and $\mathrm{H} 2)$, the relative support of $\mathrm{H} 1$ is given by the difference between $r_{M}$ obtained from two partial Mantel tests: (a) between genetic distances and $\mathrm{H} 1$, controlling for the effects of $\mathrm{H} 2$; and (b) between genetic distances and $\mathrm{H} 2$, controlling for the effects of $\mathrm{H} 1$ (i.e. $\mathrm{H} 1|\mathrm{H} 2-\mathrm{H} 2| \mathrm{H} 1$ ). If $\mathrm{H} 1$ is correct this difference is positive, otherwise $\mathrm{H} 2$ is supported. After repeating this procedure for all hypothesis pairs, a full matrix is obtained in which a hypothesis is fully supported when all values in the column are positive and the values in the associated row are negative (see Appendix S3 for a more detailed description of the method).

This analysis was repeated considering the rainy and dry season separately, to evaluate the possibility of seasonal differences in connectivity that may be masked when analysing the whole dataset. In addition, to evaluate the effect of inter-annual variation due to the El Niño phenomenon on population connectivity, we estimated the correlation between El Niño Southern Oscillation Index (SOI) and the Mantel statistic for the correlation between genetic and cost distances calculated for each month of the data period (Appendix S4).

\subsubsection{Spatial eigenfunction analysis}

Spatial eigenfunction analysis was performed as an alternative method to assess the relative contribution of geography and sea currents to the spatial genetic variation. The main difference with reciprocal causal modelling is the use of raw genetic data and redundancy analysis, instead of the pairwise genetic differences and Mantel tests that have lower statistical power (Legendre, Fortin, \& Borcard, 2015). The geographical distance matrix and the three asymmetric cost distance matrices-from IBR1, IBR2 and IBB hypotheses-were decomposed into eigenvector maps: (a) distance-based Moran's eigenvector maps (dbMEM) were obtained by decomposing pairwise Euclidean distances between populations (IBD hypothesis); (b) Moran's eigenvector maps (MEM) were obtained from a spatial weighting matrix built from a neighbourhood matrix where only populations from the same island were considered neighbours, weighted by the pairwise cost distances between neighbours (IBB hypothesis) (Dray, Legendre, \& Peres-Neto, 2006); and (c) asymmetric eigenvector maps (AEM) as the result of decomposing the directional spatial process of sea flow (IBR1 and IBR2 hypotheses). Directional connection diagrams were obtained from the sea-cost matrices built under each resistance hypothesis. For each population pair, only the direction that resulted in the highest connectivity between the populations was selected, setting the opposite direction to zero. A site-by-edge matrix was built based on the connection diagram and all edges were weighted using the connectivity values previously calculated with sea current speed and direction. Finally, AEMs were obtained by decomposing the spatial weighted matrix (Blanchet, Legendre, Maranger, Monti, \& Pepin, 2011). All eigenvectors were obtained using the r package 'adespatial' (Dray et al., 2020) and were used as predictor variables in independent redundancy analyses (RDA) for each hypothesis. RDA is a constrained ordination analysis, which seeks the linear combination of the predictor variables that best explains the variation of the multivariate response variable. Allelic frequencies for each population were Hellinger-transformed and decomposed by PCA. All the PCs that explain more than 5\% of the variation were employed as multivariate response variable in RDAs. From saturated models built for each hypothesis, the eigenvectors that best explained the genetic variation were selected using forward selection with 100,000 permutations. These significant variables were combined into a full model. Partial RDAs and variation 
partitioning with 100,000 permutations were performed to evaluate the relative contribution of the hypotheses tested. Redundancy analyses and variation partitioning were performed using the 'vegan' R package (Oksanen et al., 2018).

\section{3 | RESULTS}

After processing the raw reads with 'ipyrad', 11,624 loci were obtained. Of these, 7,176 were polymorphic, bearing a total of 23,085 SNPs. After removing replicated individuals and poorly sequenced loci, and keeping only biallelic SNPs, there were finally 746 loci and 1,806 SNPs of 240 individuals with $40.46 \%$ missing data.

\subsection{Genetic diversity, differentiation and population structure}

Averaged values across loci and populations of $H_{\mathrm{O}}, H_{\mathrm{E}}, F_{\mathrm{IS}}, G_{\mathrm{ST}}, \theta$ and Jost's $D$ are shown in Table 1 and Table S1.2. No significant relationship was found between heterozygosity and island size $\left(\mathrm{H}_{\mathrm{O}}: r=.058\right.$ $\left.p=.859 ; \mathrm{H}_{\mathrm{E}}: r=.231, p=.470\right)$. The northern population of Isabela and that of Santa Fe presented the highest value of pairwise differentiation ( $\theta=0.145$ when including the continent; $\theta=0.128$ within Galápagos), whereas the minimum value was found between the northern population of Isabela and the western population of Santa Cruz $\theta=-0.172$ when including the continent; $\theta=-0.109$ within Galápagos) (Table S1.3). AMOVA results show a low percentage of variance occurring between islands and between populations within islands, both including (1.46\% and $0.91 \%$, respectively) and excluding samples from mainland Ecuador ( $0.96 \%$ and $2.63 \%$, respectively) (Table S1.4).

PCA results showed that none of all the possible combinations of the 11 first principal components (variance explained: $28.38 \%$ ) grouped the individuals according to geography (Figures S5.1 and S5.2). Neither DAPC nor 'STRUCTURE' results were in agreement with the geographical distribution of the samples and no consensus was found regarding which K-value represents the most plausible number of clusters based on the genetic data (Figure 2a and Figures S5.3-S5.6). DAPC run with groups defined by the user-that is, groups by islands and continent, $\mathrm{K}=13$-detected highly mixed groups and a clearer genetic identity of individuals from the mainland, Santa Fe and Fernandina (Figure 2b).

\section{2 | Isolation by resistance, barrier or geographical distance}

Resistance by sea currents and low resistance to crossing landmasses (IBR2) was preferred over the competing hypotheses in the reciprocal causal modelling framework based on the relative support values of the matrix, with positive values in the IBR2 column and negative values in the corresponding row (Figure 3a). Furthermore, Mantel tests and some of the partial Mantel tests that include IBR2 and IBD as predictor hypotheses of the genetic distances were statistically significant (Figure 3b). These results did not change when analysing the rainy (from December to May) and dry seasons (from June to November) separately (Tables S1.5 and S1.6). Besides this, no significant correlation was found between monthly El Niño Southern Oscillation index and monthly Mantel's $r\left(r_{M}\right)$ comparing genetic and cost distances (IBR2), indicating a negligible effect of ocean current oscillations due to El Niño events (Figure S4.1). The isolation-by-distance (IBD) and isolation-by-resistance hypotheses (IBR1 and IBR2) were highly correlated (IBR1 IBR2: $r_{M}=.498, p<.001$; IBD IBR1: $r_{M}=.787, p<.001$; IBD IBR2: $\left.r_{M}=.757 ; p<.001\right)$.

Redundancy analyses performed with eigenvector maps as predictor variables also support IBR2 as the hypothesis that best explains the spatial genetic variability. Nine PCs retrieved from the PCA of the Hellinger-transformed allele frequencies were used as response variable in the RDAs. None of the dbMEM variables were found to be significant (IBD hypothesis). Two MEM variables (MEM4 and MEM11) significantly explained $9.40 \%$ of genetic variability included in the PCs (IBB hypothesis; $\mathrm{R}_{\mathrm{a}}^{2}=.094 ; F=2.090 ; p=.040$ ). Two AEMs built under the IBR1 hypothesis (only sea dispersal permitted) were significant (AEM2 and AEM14), explaining $10.54 \%$ of the response variability $\left(R_{a}^{2}=.105 ; F=2.237 ; p=.003\right)$. Four AEMs built under the IBR2 hypothesis (sea and inland dispersal) significantly explained $19.47 \%$ of the genetic variance (AEM3, AEM10, AEM11, AEM19; $R_{a}^{2}=.194 ; F=2.269 ; p=.003$ ) and modelled a spatial genetic structure strongly determined by the prevailing westward sea currents (Figure 4). The full model that combines all significant eigenvectors explained $28.03 \%$ of the variance $\left(R_{a}^{2}=.2803 ; F=2.022\right.$; $p=.003$ ), but only two AEMs from the IBR2 hypothesis (AEM10 and

TABLE 1 Observed heterozygosity $\left(\mathrm{H}_{\mathrm{O}}\right)$, expected heterozygosity $\left(\mathrm{H}_{\mathrm{E}}\right)$ and inbreeding coefficient $\left(\mathrm{F}_{\mathrm{IS}}\right)$ across loci and populations of Galápagos, mainland Ecuador and populations of Galápagos and the continent considered together. Indices of fixation and differentiation are also shown considering only Galápagos populations and including the continental samples

\begin{tabular}{|c|c|c|c|c|c|c|}
\hline & $\mathrm{H}_{\mathrm{O}}$ & $\mathrm{H}_{\mathrm{E}}$ & $\mathrm{F}_{\mathrm{IS}}$ & $\mathrm{F}_{\mathrm{ST}}$ estimator $-\boldsymbol{\theta}$ & $\mathrm{G}_{\mathrm{ST}}$ & Jost's D \\
\hline Galápagos & $0.045 \pm 0.001$ & $0.049 \pm 0.001$ & $0.091 \pm 0.004$ & 0.026 & 0.326 & 0.061 \\
\hline Continent & $0.048 \pm 0.004$ & $0.059 \pm 0.005$ & $0.118 \pm 0.017$ & & & \\
\hline Galápagos + Continent & $0.044 \pm 0.001$ & $0.048 \pm 0.001$ & $0.089 \pm 0.001$ & 0.035 & 0.329 & 0.052 \\
\hline
\end{tabular}

Note: All individuals from the continent were grouped into a single population. For calculation of $\mathrm{H}_{\mathrm{O}}, \mathrm{H}_{\mathrm{E}}$ and $\mathrm{F}_{\mathrm{IS}}$, populations with $\mathrm{N}<3$ were not considered (IS3). 
(a)

Clusters determined by the algorithm $k$-means $(K=5)$

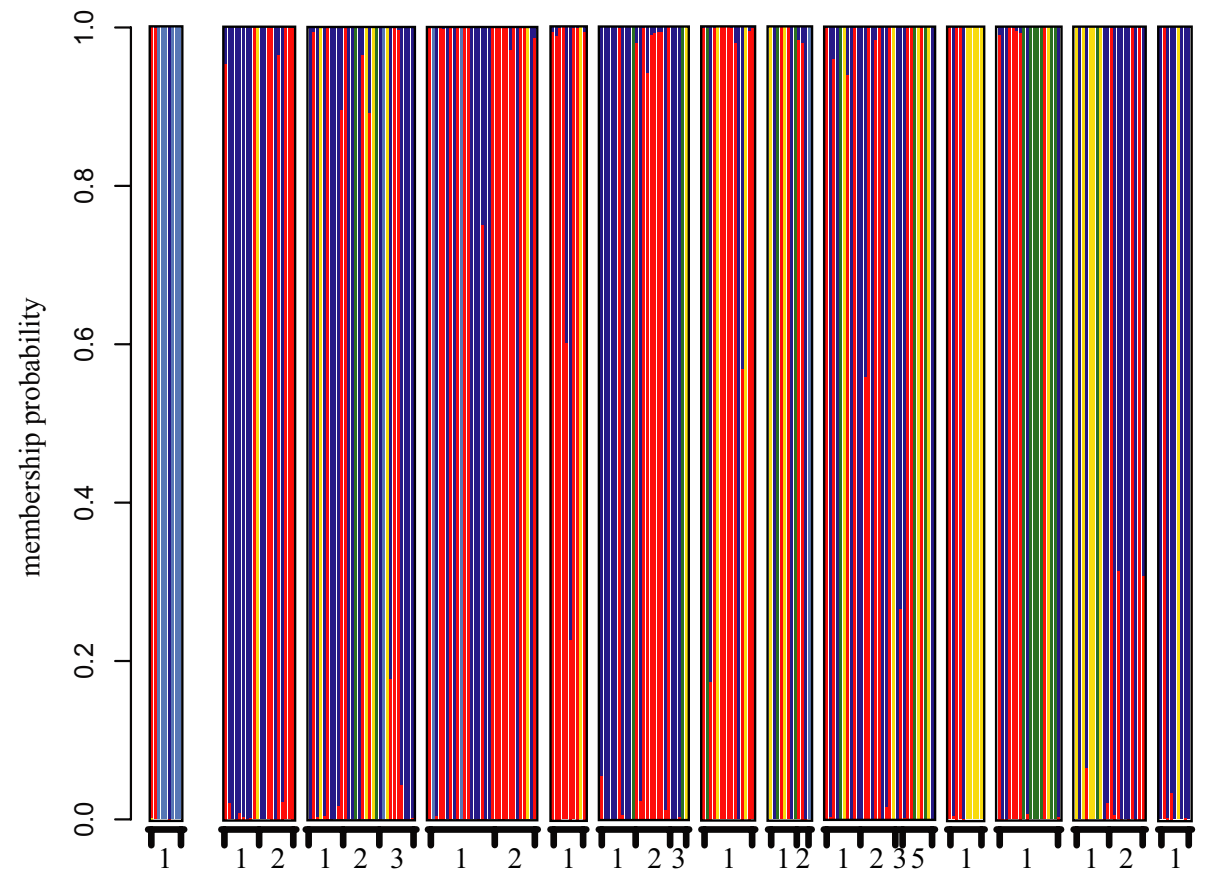

Clusters:

$\square 1 \quad \square 2 \quad \square 3 \quad \square 4 \square 5$

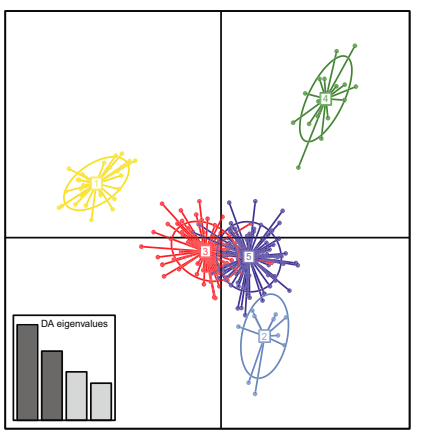

(b)
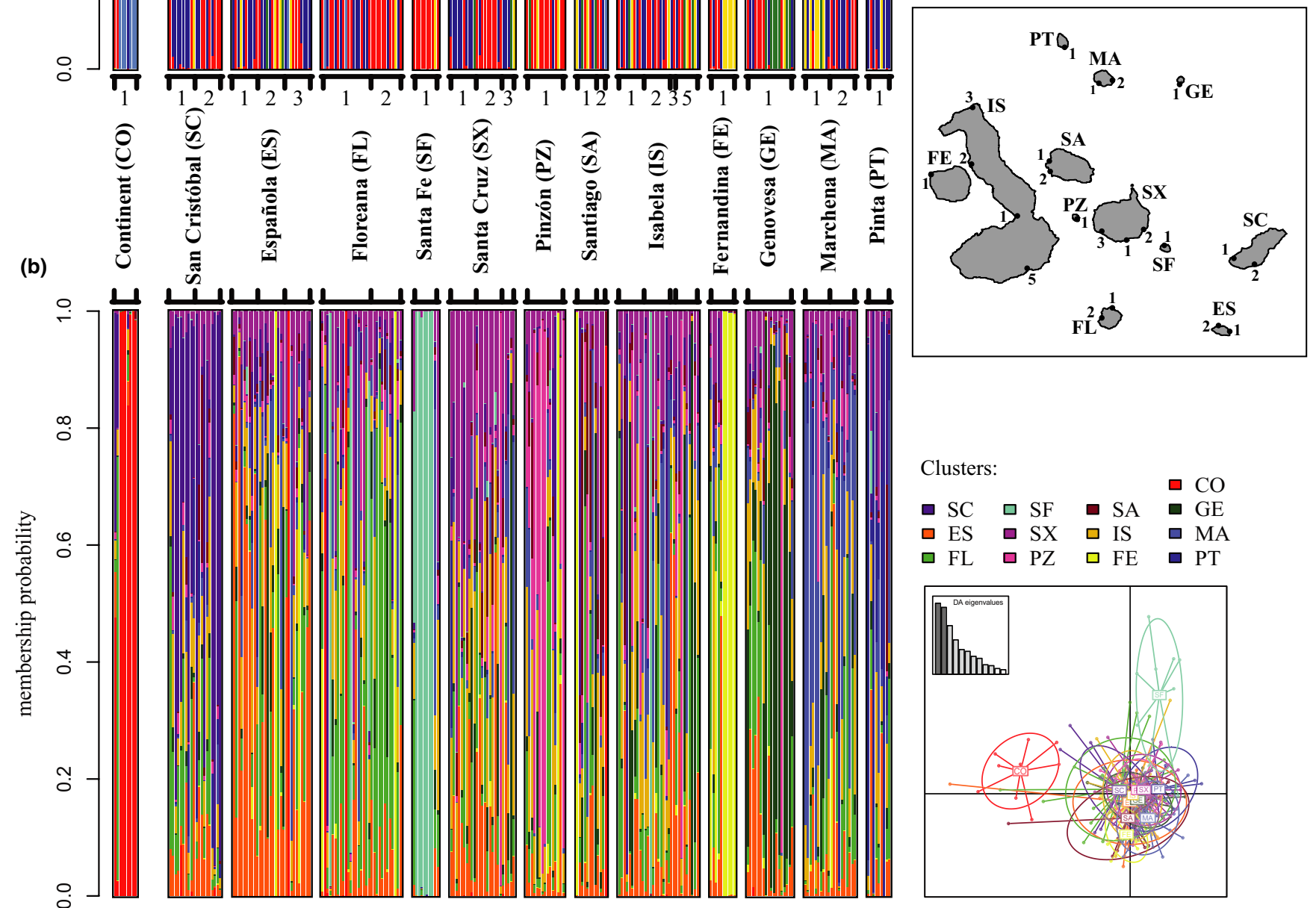

Clusters defined a priori by the user $(K=13)$

FIGURE 2 Results of the discriminant analysis of principal components (DAPC) for the genetic structure of Cryptocarpus pyriformis across the sampled area (Galápagos and mainland Ecuador). Compoplots (bar graphs) show the genetic composition of each population and scatter plots show how similar the established groups are. (a) $\mathrm{K}=5$ genetically similar groups established using the $k$-means algorithm. (b) Clusters determined using populations a priori $(\mathrm{K}=13)$ 
(a)

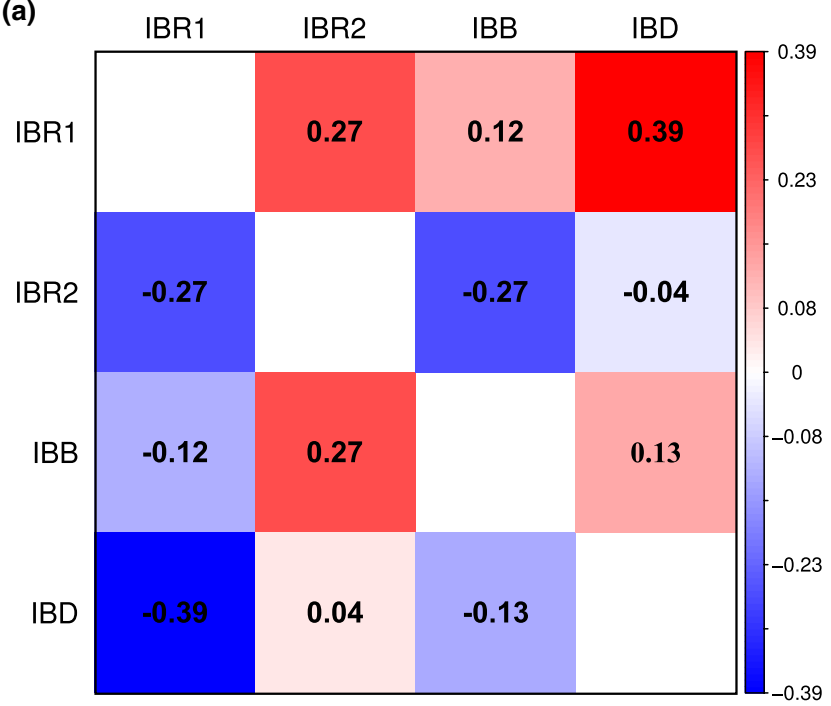

(b)

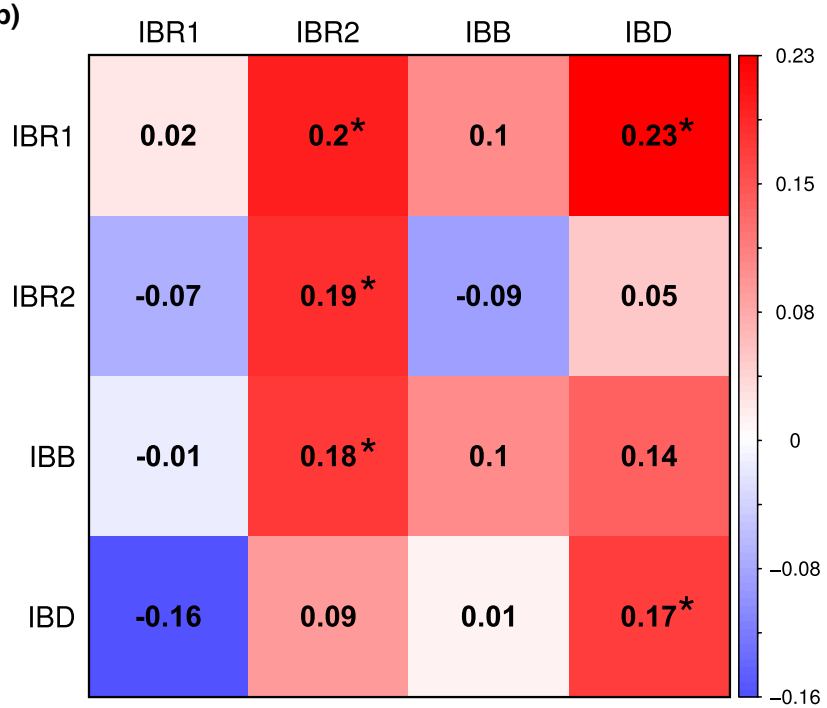

FIGURE 3 Reciprocal causal modelling results. (a) Hypothesis testing. The coefficient in each cell is the result of the difference between Mantel's $r\left(r_{M}\right)$ of two partial Mantel tests: (i) effect of the focal hypothesis (column) partialling out the effect of an alternative hypothesis (row), and (ii) effect of the alternative hypothesis partialling out the effect of the focal hypothesis (focal|alternative - alternative|focal). The colour gradient from blue to red varies according to the coefficient in the cell and indicates the relative support of the focal hypothesis. The best supported hypothesis is IBR2, as all the coefficients in the IBR2 column are positive, and negative in the corresponding row. (b) Mantel's $r$ for simple Mantel tests (diagonal) and partial Mantel tests that evaluate the effect on the genetic differentiation of a focal hypothesis (column) controlling for the effects of an alternative hypothesis (row). Statistically significant correlations $(p<.05)$ are shown by *

AEM11) and MEM4 (IBB hypothesis) were found to be significant $(p<.05)$. Results of variation partitioning showed that the relative contribution of the AEMs from the IBR2 hypothesis significantly explained $16.86 \%$ of the genetic variation $(p=.006)$, while the contribution of IBB eigenvectors was not significant $(p=.085)$ and explained $6.79 \%$ of the variance. The overlapping effect of both types of variables was $2.61 \%$ and the residual variation $73.74 \%$.

\section{4 | DISCUSSION}

Cryptocarpus pyriformis maintains high gene flow among its populations, which is revealed by low genetic differentiation and little genetic structure, even when including continental populations. This result agrees with the hypothesis of wide dispersal of C. pyriformis through thalassochory, the species being highly admixed at archipelago scale. Sea currents were found to be the main driver of genetic differentiation between islands within the Galápagos, and inland dispersal may have contributed to defining the spatial genetic pattern found within islands.

\section{1 | Thalassochorous species have high dispersal ability}

Plant diaspores adapted to sea dispersal are able to travel across long distances, even thousands of kilometres (Cerón-Souza et al., 2015; Miryeganeh et al., 2014; Nathan et al., 2008; Ridley, 1930; Takayama et al., 2008). This high dispersal ability favours species arrival and colonization of oceanic islands isolated amidst the ocean, confirmed by the fact that thalassochorous species are among the first pioneer plants on newly emerged islands (Abe, 2006; Magnússon et al., 2014; Thornton, 1997). Thalassochorous species are usually widely distributed across oceanic archipelagos (Arjona, Nogales, Heleno, \& Vargas, 2018; Vargas et al., 2014) and high inter-island gene flow has been reported for some of them, such as Calophyllum inophyllum (Hanaoka et al., 2014) and Terminalia catappa (Setsuko et al., 2017) in the Bonin Islands, and Pandanus tectorius in Hawai'i (Gallaher et al., 2017). In accordance with the high dispersal ability reported for thalassochorous species, the salt bush has been able to colonize Galápagos from the continent (about 1,000 km away), possibly several times independently. The species has spread across all the 13 largest islands of the archipelago and populations maintain high genetic connectivity.

\subsection{Oceanic currents as dispersal vector}

The high dispersal ability of thalassochorous plants has led many authors to consider them as panmictic species for which no differentiation is expected, considering the ocean as barrier-free for these species (Carlquist, 1967; Nathan et al., 2008; Paulay \& Meyer, 2002). However, genetic studies have shown that this statement is not ubiquitous, as some level of genetic structuring has been found in sea-dispersed plants, not only mediated by land barriers but because of sea current properties, in particular current speed and direction (Cerón-Souza et al., 2015; Gallaher et al., 2017; Guo et al., 2016; Hanaoka et al., 2014; Hodel 


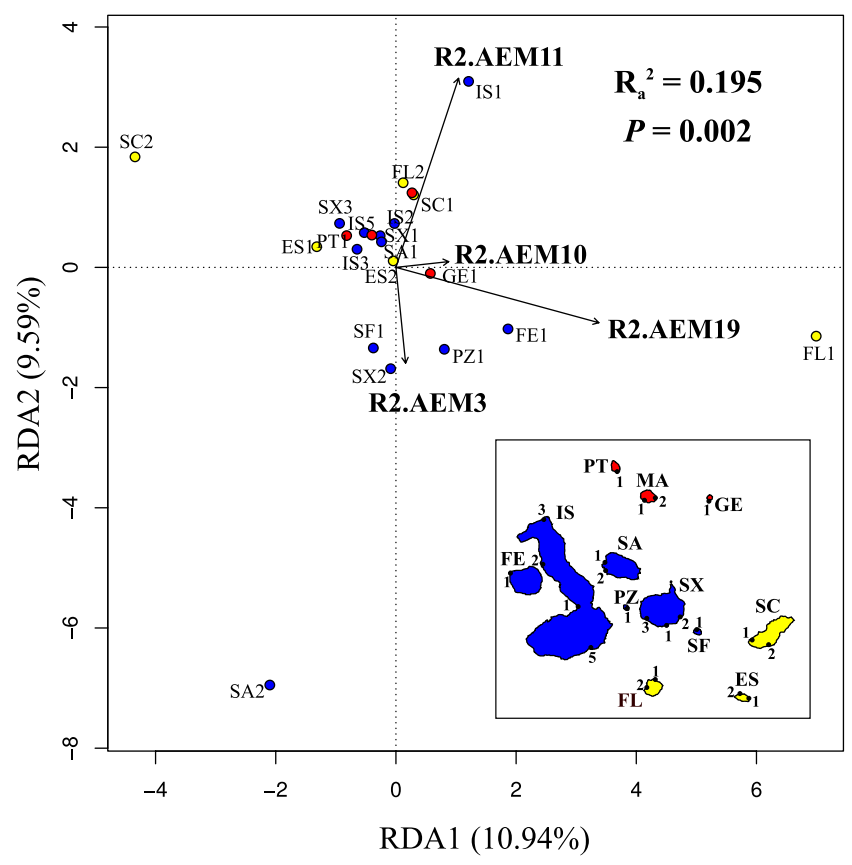

FIGURE 4 Redundancy analysis (RDA) biplot showing the two first canonical axes (RDA1 and RDA2 - percentage of total variation explained shown in brackets) of the canonical ordination of the four significant asymmetric eigenvector maps (AEM variables-arrows) built under the hypothesis that considers together maritime and terrestrial dispersal (IBR2), and the 23 Galápagos populations (dots coloured according to geographical position-see map-legend). Island abbreviations: $\mathrm{GE}=$ Genovesa, $\mathrm{MA}=$ Marchena, $\mathrm{PT}=$ Pinta, $\mathrm{SF}=$ Santa Fe, SX = Santa Cruz, $\mathrm{SA}=$ Santiago, $\mathrm{PZ}=$ Pinzón, IS = Isabela, FE = Fernandina, $\mathrm{SC}=\mathrm{San}$ Cristóbal, $\mathrm{ES}=$ Española, $\mathrm{FL}=$ Floreana

et al., 2018; Miryeganeh et al., 2014; Ngeve, Van der Stocken, Menemenlis, Koedam, \& Triest, 2016; Wee et al., 2014). Despite the importance of sea currents in long-distance dispersal, few studies have statistically assessed their role in genetic differentiation and distribution of terrestrial organisms. Nevertheless, several authors (Fajardo et al., 2019; Harvey, 1994) have evaluated the relationship between sea currents and species distributions, and also, for instance, the relationship between sea currents and gene flow of Caribbean lizards (Calsbeek \& Smith, 2003) and mangroves (Hodel et al., 2018). All of these found a significant contribution of sea currents to the distribution and genetic patterns. In agreement with these studies, genetic differentiation of the Galápagos salt bush populations is correlated to direction and speed of sea currents, as shown by reciprocal causal modelling and redundancy analysis results. This is as expected for a sea-dispersed species. In addition, geographical and genetic distances were revealed to be significantly correlated by Mantel test (Figure 3b), as cost-distances increase not only with the resistance to dispersal driven by oceanic currents, but geographical distance as well. Similar results were found in mangroves by Hodel et al. (2018).

In addition to sea dispersal, our results indicate that inland gene flow is likely at work for this coastal species, as only the hypothesis that combines resistance by maritime and terrestrial dispersal (IBR2) was consistently selected by both reciprocal causal modelling and redundancy analysis. Finches and lizards that consume salt bush fruits might act as potential inland dispersers of this species (Heleno et al., 2011, 2013). However, analysis of genetic data mainly from the nuclear genome prevents distinguishing between the seed and pollen flow contributions to such short-distance gene flow. Indeed, insect-mediated pollen dispersal has been proposed to explain the connectivity found across the Panama Isthmus between populations of Hibiscus tiliaceus (Takayama et al., 2008) and Ipomoea pescaprae (Miryeganeh et al., 2014). Cryptocarpus pyriformis is abundant in coastal xeric areas of the archipelago. This pattern favours short inland pollen dispersal by insects and birds, both effective pollinators of the species (Hervías-Parejo \& Traveset, 2018; Olesen et al., 2018). The respective contribution of pollen versus seed dispersal in explaining within-islands isolation by distance remains an open question.

\subsection{Quaternary climatic and sea-level changes affected coastal plant populations}

Historical geological changes-such as the emergence and subsidence of oceanic islands (e.g. Christie et al., 1992)-together with climatic and sea-level changes might have altered oceanic currents (Gillespie et al., 2012). In addition, coastal habitats are expected to have suffered frequent disturbance due to past climate changes and variation in sea level, causing successive episodes of flooding, drought and other extreme meteorological events, possibly leading to local extinctions (Kudoh, Shimamura, Takayama, \& Whigham, 2006; Ngeve et al., 2016) and further recolonizations (Ali $\&$ Aitchison, 2014). Such metapopulation dynamics have probably been dramatically catalysed by active volcanism, which has transformed the landscape of many of the Galápagos Islands for more than two million years since their emergence (Geist, Snell, Snell, Goddard, \& Kurz, 2014). Volcanism and sea-level changes may have had an impact on the demographic history of coastal plant species, likely causing profound changes in their effective population sizes through time. As a consequence, historical processes are expected to have left an imprint on the gene flow detected among populations of the Galápagos salt bush, almost ruling out the possibility of finding any stronger relationship with the current ocean circulation (Hodel et al., 2018). In addition to the weak genetic structure found for the Galápagos populations in this study, the low heterozygosity and its lack of relationship with island size could indicate a recent colonization or recolonization of the archipelago, or at least that the populations underwent similar demographic processes in the recent past. Further avenues for research are opened to investigate the demographic history of the Galápagos salt bush and the clues it provides regarding the geological history of the archipelago.

Although some open questions remain, our study highlights the usefulness of combining methods developed under a joint landscape and seascape genetic framework, to statistically assess how the 
surrounding environment modulates gene flow between populations of coastal plants.

\section{ACKNOWLEDGEMENTS}

We thank Emilio Cano and Morgan Gueuning for their help in the wet lab and all N.A.'s group for their advice on technical issues, Raphaël Leblois for his advice on population genetic analyses, Javier Morente for useful discussion about the manuscript, and two anonymous referees, the Chief and Handling Editors for their valuable comments that helped to improve the manuscript. We also thank the Galápagos fieldwork team, the Charles Darwin Foundation and the Galápagos National Park, which facilitated plant material sampling (permit numbers: PC-46-14 and PC-21-15). YA was funded by the Ministerio de Economía y Competitividad (Spain) (BES-2013-062843; EEBB-I-15-10273; EEBB-I-16-11437). This study is framed within a project also financed by the Ministerio de Economía y Competitividad (CGL2012-C02-01). The manuscript was edited by Guido Jones, currently funded by the Cabildo de Tenerife, under the TFinnova Programme supported by MEDI and FDCAN funds.

\section{DATA AVAILABILITY STATEMENT}

Final assembled and filtered SNP dataset and scripts are stored and publicly accessible in figshare repository (https://doi.org/10.6084/ m9.figshare.12529523.v1). Modified rWind functions to work with sea current data can be found in GitHub repository (https:// github.com/jabiologo/rWind/tree/master/man). Raw demultiplexed sequences of the ddRADseq dataset are available on NCBI SRA (BioProject Accession PRJNA655805).

\section{ORCID}

Yurena Arjona (iD https://orcid.org/0000-0002-1851-1664

Javier Fernández-López iD https://orcid.

org/0000-0003-4352-0252

Miguel Navascués (iD https://orcid.org/0000-0001-8342-6047

Nadir Alvarez iD https://orcid.org/0000-0002-0729-166X

Manuel Nogales iD https://orcid.org/0000-0002-5327-3104

Pablo Vargas iD https://orcid.org/0000-0003-4502-0382

\section{REFERENCES}

Abe, T. (2006). Colonization of Nishino-Shima island by plants and arthropods 31 years after eruption. Pacific Science, 60(3), 355-365. https://doi.org/10.1353/psc.2006.0014

Ali, J. R., \& Aitchison, J. C. (2014). Exploring the combined role of eustasy and oceanic island thermal subsidence in shaping biodiversity on the Galápagos. Journal of Biogeography, 41(7), 1227-1241. https://doi. $\operatorname{org} / 10.1111 / \mathrm{jbi} .12313$

Arjona, Y., Nogales, M., Heleno, R., \& Vargas, P. (2018). Long-distance dispersal syndromes matter: Diaspore-trait effect on shaping plant distribution across the Canary Islands. Ecography, 41, 805-814. https://doi.org/10.1111/ecog.02624

Blanchet, F. G., Legendre, P., Maranger, R., Monti, D., \& Pepin, P. (2011). Modelling the effect of directional spatial ecological processes at different scales. Oecologia, 166(2), 357-368. https://doi.org/10.1007/ s00442-010-1867-y
Bolger, A. M., Lohse, M., \& Usadel, B. (2014). Trimmomatic: A flexible trimmer for Illumina sequence data. Bioinformatics, 30(15), 21142120. https://doi.org/10.1093/bioinformatics/btu170

Braun, C. D., Galuardi, B., \& Thorrold, S. R. (2018). HMMoce: An R package for improved geolocation of archival-tagged fishes using a hidden Markov method. Methods in Ecology and Evolution, 9(5), 1212-1220. https://doi.org/10.1111/2041-210X.12959

Calsbeek, R., \& Smith, T. B. (2003). Ocean currents mediate evolution in island lizards. Nature, 426(December), 522-555. https://doi. org $/ 10.1038 /$ nature02143

Carlquist, S. (1967). The biota of long-distance dispersal. V. Plant dispersal to Pacific Islands. Bulletin of the Torrey Botanical Society, 94(3), 129-162.

Cerón-Souza, I., Gonzalez, E. G., Schwarzbach, A. E., Salas-Leiva, D. E., Rivera-Ocasio, E., Toro-Perea, N., ... McMillan, W. O. (2015). Contrasting demographic history and gene flow patterns of two mangrove species on either side of the Central American Isthmus. Ecology and Evolution, 5(16), 3486-3499. https://doi.org/10.1002/ ece3.1569

Christie, D. M., Duncan, R. A., McBirney, A. R., Richards, M. A., White, W. M., Harpp, K. S., \& Fox, C. G. (1992). Drowned islands downstream from the Galapagos hotspot imply extended speciation times. Nature, 355, 246-248. https://doi.org/10.1038/355246a0

Cushman, S. A., Wasserman, T. N., Landguth, E. L., \& Shirk, A. J. (2013). Re-evaluating causal modeling with Mantel tests in landscape genetics. Diversity, 5(1), 51-72. https://doi.org/10.3390/d5010051

Danecek, P., Auton, A., Abecasis, G., Albers, C. A., Banks, E., De Pristo, M. A., ... Durbin, R. (2011). The variant call format and VCFtools. Bioinformatics, 27(15), 2156-2158. https://doi.org/10.1093/bioin formatics/btr330

Darwin, C. (1859). On the origin of species by means of natural selection, or the preservation of favoured races in the struggle for life. London: John Murray.

Dray, S., Bauman, D., Blanchet, G., Borcard, D., Clappe, S., Guenard, G., .. Wagner, H. H. (2020). adespatial: Multivariate multiscale spatial analysis (Version 0.3-8) [Computer software]. Retrieved from https:// CRAN.R-project.org/package $=$ adespatial

Dray, S., Legendre, P., \& Peres-Neto, P. R. (2006). Spatial modelling: A comprehensive framework for principal coordinate analysis of neighbour matrices (PCNM). Ecological Modelling, 196(3-4), 483-493. https://doi.org/10.1016/j.ecolmodel.2006.02.015

Eaton, D. A. R. (2014). PyRAD: Assembly of de novo RADseq loci for phylogenetic analyses. Bioinformatics, 30(13), 1844-1849. https:// doi.org/10.1093/bioinformatics/btu121

Esteves, C. F., Costa, J. M., Vargas, P., Freitas, H., \& Heleno, R. H. (2015). On the limited potential of Azorean fleshy fruits for oceanic dispersal. PLoS One, 10(10), e0138882. https://doi.org/10.1371/journ al.pone.0138882

Evanno, G., Regnaut, S., \& Goudet, J. (2005). Detecting the number of clusters of individuals using the software STRUCTURE: A simulation study. Molecular Ecology, 14(8), 2611-2620. https://doi. org/10.1111/j.1365-294X.2005.02553.x

Excoffier, L., Smouse, P. E., \& Quattro, J. M. (1992). Analysis of molecular variance inferred from metric distances among DNA haplotypes: Application to human mitochondrial DNA restriction data. Genetics, 131, 479-491.

Fajardo, J., Mateo, R. G., Vargas, P., Fernández-Alonso, J. L., GómezRubio, V., Felicísimo, Á. M., \& Muñoz, J. (2019). The role of abiotic mechanisms of long-distance dispersal in the American origin of the Galápagos flora. Global Ecology and Biogeography, 28(11), 1610-1620. https://doi.org/10.1111/geb.12977

Falush, D., Stephens, M., \& Pritchard, J. K. (2003). Inference of population structure using multilocus genotype data: Linked loci and correlated allele frequencies. Genetics, 164(4), 1567-1587. 
Fernández-López, J., \& Schliep, K. (2018). rWind: Download, edit and include wind data in ecological and evolutionary analysis. Ecography, 42, 1-7.

Gallaher, T., Callmander, M. W., Buerki, S., Setsuko, S., \& Keeley, S. C. (2017). Navigating the 'broad freeway': Ocean currents and inland isolation drive diversification in the Pandanus tectorius complex (Pandanaceae). Journal of Biogeography, 44(7), 1598-1611.

Geist, D., Snell, H., Snell, H., Goddard, C., \& Kurz, M. (2014). Paleogeography of the Galápagos Islands and biogeographical implications. In K. S. Harpp, E. Mittelstaedt, N. D'Ozouville, \& D. W. Graham (Eds.), The Galapagos: A natural laboratory for the Earth Sciences (pp. 145-166). Washington DC, USA: American Geophysical Union.

Gillespie, R. G., Baldwin, B. G., Waters, J. M., Fraser, C. I., Nikula, R., \& Roderick, G. K. (2012). Long-distance dispersal: A framework for hypothesis testing. Trends in Ecology and Evolution, 27(1), 47-55. https:// doi.org/10.1016/j.tree.2011.08.009

Guja, L. K., Merritt, D. J., \& Dixon, K. W. (2010). Buoyancy, salt tolerance and germination of coastal seeds: Implications for oceanic hydrochorous dispersal. Functional Plant Biology, 37(12), 1175-1186. https://doi.org/10.1071/FP10166

Guo, Z., Huang, Y., Chen, Y., Duke, N. C., Zhong, C., \& Shi, S. (2016). Genetic discontinuities in a dominant mangrove Rhizophora apiculata (Rhizophoraceae) in the Indo-Malesian region. Journal of Biogeography, 43(9), 1856-1868.

Hanaoka, S., Chien, C.-T., Chen, S.-Y., Watanabe, A., Setsuko, S., \& Kato, K. (2014). Genetic structures of Calophyllum inophyllum L., a tree employing sea-drift seed dispersal in the northern extreme of its distribution. Annals of Forest Science, 71(5), 575-584.

Harvey, L. E. (1994). Spatial patterns of inter-island plant and bird species movements in the Galapagos Islands. Journal of the Royal Society of New Zealand, 24(I), 45-63.

Heleno, R., Blake, S., Jaramillo, P., Traveset, A., Vargas, P., \& Nogales, M. (2011). Frugivory and seed dispersal in the Galápagos: What is the state of the art? Integrative Zoology, 6, 110-128.

Heleno, R., Olesen, J. M., Nogales, M., Vargas, P., \& Traveset, A. (2013). Seed dispersal networks in the Galápagos and the consequences of alien plant invasions. Proceedings of the Royal Society B, 280, 20122112.

Heleno, R., \& Vargas, P. (2015). How do islands become green? Global Ecology and Biogeography, 24, 518-526. https://doi.org/10.1111/ geb.12273

Hervías-Parejo, S., \& Traveset, A. (2018). Pollination effectiveness of opportunistic Galápagos birds compared to that of insects: From fruit set to seedling emergence. American Journal of Botany, 105(7), 1142-1153. https://doi.org/10.1002/ajb2.1122

Hijmans, R. J. (2018). raster: Geographic data analysis and modeling. Retrieved fromhttps://cran.r-project.org/package=raster

Hodel, R. G. J., Knowles, L. L., McDaniel, S. F., Payton, A. C., Dunaway, J. F., Soltis, P. S., \& Soltis, D. E. (2018). Terrestrial species adapted to sea dispersal: Differences in propagule dispersal of two Caribbean mangroves. Molecular Ecology, 27(22), 4612-4626. https://doi. org/10.1111/mec.14894

Jaramillo Díaz, P., Guézou, A., Mauchamp, A., \& Tye, A. (2018).CDF checklist of galapagos flowering plants. In F. Bungartz, H. Herrera, P. Jaramillo, N. Tirado, G. Jiménez-Uzcátegui, F. Ruiz, \& F. Ziemmeck (Eds.), Charles Darwin foundation galapagos species checklist. Puerto Ayora, Galápagos (Ecuador): Charles Darwin Foundation.

Jombart, T., Devillard, S., \& Balloux, F. (2010). Discriminant analysis of principal components: A new method for the analysis of genetically structured populations. BMC Genetics, 11(1), 94. https://doi. org/10.1186/1471-2156-11-94

Jost, L. (2008). GST and its relatives do not measure differentiation. Molecular Ecology, 17, 4015-4026.
Kamvar, Z. N., Tabima, J. F., \& Grünwald, N. J. (2014). Poppr : An R package for genetic analysis of populations with clonal, partially clonal, and/or sexual reproduction. PeerJ, 2, e281.

Keenan, K., Mcginnity, P., Cross, T. F., Crozier, W. W., \& Prodöhl, P. A. (2013). DiveRsity: An R package for the estimation and exploration of population genetics parameters and their associated errors. Methods in Ecology and Evolution, 4, 782-788.

Kudoh, H., Shimamura, R., Takayama, K., \& Whigham, D. F. (2006). Consequences of hydrochory in Hibiscus. Plant Species Biology, 21(3), 127-133. https://doi.org/10.1111/j.1442-1984.2006.00158.x

Legendre, P., Fortin, M., \& Borcard, D. (2015). Should the Mantel test be used in spatial analysis? Methods in Ecology and Evolution, 6(11), 1239-1247. https://doi.org/10.1111/2041-210X.12425

Magnússon, B., Magnússon, S. H., Ólafsson, E., \& Sigurdsson, B. D. (2014). Plant colonization, succession and ecosystem development on Surtsey with reference to neighbouring islands. Biogeosciences, 11(19), 5521-5537. https://doi.org/10.5194/bg-11-5521-2014

Manel, S., \& Holderegger, R. (2013). Ten years of landscape genetics. Trends in Ecology and Evolution, 28(10), 614-621. https://doi. org/10.1016/j.tree.2013.05.012

Mantel, N. (1967). The detection of disease clustering and a generalized regression approach. Cancer Research, 27(2), 209-220.

Mastretta-Yanes, A., Arrigo, N., Alvarez, N., Jorgensen, T. H., Piñero, D., \& Emerson, B. C. (2015). Restriction site-associated DNA sequencing, genotyping error estimation and de novo assembly optimization for population genetic inference. Molecular Ecology Resources, 15, 28-41.

Miryeganeh, M., Takayama, K., Tateishi, Y., \& Kajita, T. (2014). Long-distance dispersal by sea-drifted seeds has maintained the global distribution of Ipomoea pes-caprae subsp. brasiliensis (Convolvulaceae). PLoS One, 9(4), e91836. https://doi.org/10.1371/ journal.pone.0091836

Muñoz, J., Felicísimo, Á. M., Cabezas, F., Burgaz, A. R., \& Martínez, I. (2004). Wind as a long-distance dispersal vehicle in the southern hemisphere. Science, 304, 1144-1147. https://doi.org/10.1126/scien ce.1095210

Nakanishi, H. (1988). Dispersal ecology of the maritime plants in the Ryukyu Islands. Japan. Ecological Research, 3(2), 163-173. https://doi. org/10.1007/BF02346937

Nathan, R., Schurr, F. M., Spiegel, O., Steinitz, O., Trakhtenbrot, A., \& Tsoar, A. (2008). Mechanisms of long-distance seed dispersal. Trends in Ecology and Evolution, 23(11), 638-647. https://doi.org/10.1016/j. tree.2008.08.003

Nei, M., \& Chesser, R. K. (1983). Estimation of fixation indices and gene diversities. Annals of Human Genetics, 47(3), 253-259. https://doi. org/10.1111/j.1469-1809.1983.tb00993.x

Ngeve, M. N., Van der Stocken, T., Menemenlis, D., Koedam, N., \& Triest, L. (2016). Contrasting effects of historical sea level rise and contemporary ocean currents on regional gene flow of Rhizophora racemosa in eastern Atlantic mangroves. PLoS One, 11(3), e0150950. https:// doi.org/10.1371/journal.pone.0150950

Oksanen, J., Blanchet, G., Friendly, M., Kindt, R., Legendre, P., McGlinn, D., ...Wagner, H. (2018). vegan: Community Ecology package. Retrieved from https://cran.r-project.org/package=vegan

Olesen, J. M., Damgaard, C. F., Fuster, F., Heleno, R. H., Nogales, M., Rumeu, B., ... Traveset, A. (2018). Disclosing the double mutualist role of birds on Galápagos. Scientific Reports, 8(1), 57. https://doi. org/10.1038/s41598-017-17592-8

Paulay, G., \& Meyer, C. (2002). Diversification in the tropical Pacific: Comparisons between marine and terrestrial systems and the importance of founder speciation. Integrative and Comparative Biology, 42(5), 922-934. https://doi.org/10.1093/icb/42.5.922

Peakall, R., \& Smouse, P. E. (2006). GenAIEx 6: Genetic analysis in Excel. Population genetic software for teaching and research. 
Molecular Ecology Notes, 6, 288-295. https://doi.org/10.1111/ j.1471-8286.2005.01155.x

Peakall, R., \& Smouse, P. E. (2012). GenAlEx 6.5: Genetic analysis in Excel. Population genetic software for teaching and research-an update. Bioinformatics, 28(19), 2537-2539.

Pritchard, J. K., Stephens, M., \& Donnelly, P. (2000). Inference of population structure using multilocus genotype data. Genetics, 155(2), 945-959.

Puechmaille, S. J. (2016). The program STRUCTURE does not reliably recover the correct population structure when sampling is uneven: Subsampling and new estimators alleviate the problem. Molecular Ecology Resources, 16(3), 608-627.

R Development Core Team. (2017). R: A language and environment for statistical computing. Vienna, Austria: R Foundation for Statistical Computing. Retrieved from https://www.r-project.org/

Ridley, H. N. (1930). The dispersal of plants throughout the world. Ashford, Kent: L. Reeve \& Co.

Riginos, C., \& Liggins, L. (2013). Seascape genetics: Populations, individuals, and genes marooned and adrift. Geography Compass, 7(3), 197-216. https://doi.org/10.1111/gec3.12032

Rosenberg, N. A. (2004). DISTRUCT: A program for the graphical display of population structure. Molecular Ecology Notes, 4(1), 137-138. https://doi.org/10.1046/j.1471-8286.2003.00566.x

Rousset, F. (1997). Genetic differentiation and estimation of gene flow from F-statistics under isolation by distance. Genetics, 145, $1219-1228$

Rousset, F. (2008). GENEPOP'007: A complete re-implementation of the GENEPOP software for Windows and Linux. Molecular Ecology Resources, 8(1), 103-106. https://doi. org/10.1111/j.1471-8286.2007.01931.x

Selkoe, K. A., D'Aloia, C. C., Crandall, E. D., lacchei, M., Liggins, L., Puritz, J. B., ... Toonen, R. J. (2016). A decade of seascape genetics: Contributions to basic and applied marine connectivity. Marine Ecology Progress Series, 554, 1-19. https://doi.org/10.3354/meps1 1792

Setsuko, S., Ohtani, M., Sugai, K., Nagamitsu, T., Kato, H., \& Yoshimaru, H. (2017). Genetic variation of pantropical Terminalia catappa plants with sea-drifted seeds in the Bonin Islands: Suggestions for transplantation guidelines. Plant Species Biology, 32(1), 13-24.

Smouse, P. E., Long, J. C., \& Sokal, R. R. (1986). Multiple regression and correlation extensions of the Mantel test of matrix correspondence. Systematic Zoology, 35(4), 627-632. https://doi.org/10.2307/2413122
Takayama, K., Tateishi, Y., Murata, J., \& Kajita, T. (2008). Gene flow and population subdivision in a pantropical plant with sea-drifted seeds Hibiscus tiliaceus and its allied species: Evidence from microsatellite analyses. Molecular Ecology, 17(11), 2730-2742.

Thornton, I. (1997). Krakatau: The destruction and reassembly of an island ecosystem. Cambridge, MA: Harvard University Press.

Traveset, A., Heleno, R. H., Chamorro, S., Vargas, P., Mcmullen, C. K., Castro-Urgal, R., ... Olesen, J. M. (2013). Invaders of pollination networks in the Galápagos Islands : Emergence of novel communities. Proceedings of the Royal Society B, 280, 20123040.

van der Pijl, L. (1982). Principles of dispersal in higher plants. Berlin: Springer-Verlag.

van Etten, J. (2017). R package gdistance: Distances and routes on geographical grids. Journal of Statistical Software, 76(13), jss.v076.i13.

Vargas, P., Nogales, M., Jaramillo, P., Olesen, J. M., Traveset, A., \& Heleno, R. (2014). Plant colonization across the Galápagos Islands: Success of the sea dispersal syndrome. Botanical Journal of the Linnean Society, 174(3), 349-358. https://doi.org/10.1111/boj.12142

Wee, A. K. S., Takayama, K., Asakawa, T., Thompson, B., Onrizal, S. S. Xuan Tung, N., ... Webb, E. L. (2014). Oceanic currents, not land masses, maintain the genetic structure of the mangrove Rhizophora mucronata Lam. (Rhizophoraceae) in Southeast Asia. Journal of Biogeography, 41(5), 954-964.

Weir, B. S., \& Cockerham, C. C. (1984). Estimating F-Statistics for the analysis of population structure. Evolution, 38(6), 1358-1370.

Wiggins, I. L., \& Porter, D. M. (1971). Flora of the Galápagos Islands. Stanford, California: Stanford University Press.

\section{SUPPORTING INFORMATION}

Additional supporting information may be found online in the Supporting Information section.

How to cite this article: Arjona Y, Fernández-López J, Navascués M, Alvarez N, Nogales M, Vargas P. Linking seascape with landscape genetics: Oceanic currents favour colonization across the Galápagos Islands by a coastal plant. J Biogeogr. 2020;00:1-12. https://doi.org/10.1111/jbi.13967 